\title{
Fault Diagnosis of a Voltage-Fed PWM Inverter for a Three-parallel Power Conversion System in a Wind Turbine
}

\author{
Young-Jong $\mathrm{Ko}^{*}$ and Kyo-Beum Lee ${ }^{\dagger}$ \\ $\dagger^{\dagger *}$ Division of Electrical and Computer Engineering, Ajou University, Suwon, Korea
}

\begin{abstract}
In this paper, a fault diagnosis method based on fuzzy logic for the three-parallel power converter in a wind turbine system is presented. The method can not only detect both open and short faults but can also identify faulty switching devices without additional voltage sensors or an analysis modeling of the system. The location of a faulty switch can be indicated by six-patterns of a stator current vector and the fault switching device detection is achieved by analyzing the current vector. A fault tolerant algorithm is also presented to maintain proper performance under faulty conditions. The reliability of the proposed fault detection technique has been proven by simulations and experiments with a $10 \mathrm{~kW}$ simulator.
\end{abstract}

Key Words: Fault diagnosis, Permanent Magnet Synchronous Generator (PMSG), Three-parallel operation, VSI-PWM Inverter

\section{INTRODUCTION}

In recent years, the interest in renewable energy has been increasing in an effort to overcome the environmental problems of fossil fuel and nuclear energy. Among the renewable energy sources wind power generation has especially attracted the notice of the world and many papers have been written on the subject. In high capacity wind power generation systems, a high power converter is required for the effective use of wind energy and due to financial constraints. High-rated power converters such as three-parallel separate converters can be applied to a high power conversion system for reducing the capacity of each switching device. The rated power of a single converter can be reduced to $1 / 3$ through three-parallel operation. However, there are some weaknesses in three-parallel converters. Parallel converters are more complex than a single converter due to an increase in the number of switching devices. There is also a reliability problem due to a circulating current.

There are several types of fault such as controller faults, motor faults, current sensor faults, switching device faults, and dc bus faults [1], [2]. Switching devices such as IGBT, MOSFET, and BJT are the weakest components. As a result, these components in a power conversion system are prone to be destroyed by faults.

Switching device faults can be classified into short switch fault and open switch fault. A short switch fault not only

\footnotetext{
Manuscript received May 24, 2010; revised Aug. 24, 2010

$\dagger$ Corresponding Author: kyl@ajou.ac.kr

Tel: +82-31-219-2376, Fax: +82-31-212-9531, Ajou Univ.

* Division of Electrical and Computer Engineering, Ajou Univ., Suwon, Korea
}

generates an abnormal over-current in the power conversion system and the generator but also causes some secondary problems like the demagnetization of the synchronous generator. In case of a short switch fault, the entire system should be shut down immediately for safety. An open switch fault does not require halting operation, but the noise and the vibrations can be induced in the generator and the system. Furthermore, the over-current can flow into healthy switches and can cause additional faults in these switches. Therefore, if an open switch fault is not handled immediately, it can cause secondary problems in the generator and other devices. It is essential to monitor switching device faults and to identify in which device the fault has occurred to reduce the cost of repairs and to improve the stability and reliability.

Rebeiro researched four methods to diagnose an open faulty switch in a voltage-fed asynchronous machine drive with measured voltage signals at certain points. These methods require additional voltage sensors and have difficulty in measuring voltages at certain points [3]. Jung proposed a fault detection technique using the voltage distortion in switches [4]. Peuget suggested two methods which are based on an analysis of the current vector trajectory and the instantaneous frequency for detecting faults. However, the technique using an analysis of the instantaneous frequency cannot identify faulty switches [5]. Zidani proposed a fuzzy based technique which detects and indentifies faulty switches in a voltage-fed PWM inverter for an induction motor drive using the Concordia current patterns. This method was applied in single inverter operation [6], [7]. Khomfoi proposed a fault diagnostic system to detect and identify the faulty location in a multilevel inverter using a neural network algorithm. However, this technique requires 
computational effort [8]

In this paper, a fuzzy based fault diagnostic method for three-parallel operation is proposed without the need for additional sensors or computational effort. This technique can detect switching device faults in a three-parallel power converter by analyzing the stator current patterns within a maximum of two current periods. Open switch faults can be easily detected by the proposed technique and short switch faults can be detected by installing fuses on each of the switches in series [9]. When a short switch fault occurs, the over-current will flow and a fuse will blow. After the fuse is blown, the situation is analogous to that of open switch faults. Therefore, the same fault diagnostic method can be used.

A fault tolerant algorithm for appropriate performance under switching device faults is also presented. The proper performance can be guaranteed by reconfiguring the power converter.

\section{SySTEM CONFIGURATION}

A wind power system with a three-parallel power converter using a permanent magnet synchronous generator (PMSG) is illustrated in Fig. 1. The power converter consist of a machine side converter (MSC) to control the torque and the power factor of the PMSG, a DC-link, and a grid side converter (GSC) to control output power factor. The PMSG can generate power using the mechanical torque produced by the wind. The maximum power point tracking (MPPT) for maintaining maximum power generation during variations in wind strength is performed by the MSC. This is done by torque control and the torque reference for the maximum output power under variable wind can be calculated by Eq. (1).

$$
T_{e}^{*}=K_{\text {blade }} \omega_{\text {balde }}^{2}-B \omega_{\text {blade }}
$$

where, $\omega_{\text {blade }}$ is the rotational speed of the blade, $K_{\text {blade }}$ is the blade coefficient, and $B$ is the friction coefficient.

The Park-PLL algorithm in the GSC estimates the phase angle using the grid-side voltage. The GSC maintains a fixed DC-link voltage by controlling the q-axis current and the maximum of the output power factor by controlling the d-axis current [10].

Converters are directly connected to the grid with an L-filter or an LCL-filter for reducing the current harmonics produced by PWM switching. A L-filter is mostly used but the demand for LCL-filters is increasing in high power systems. Because the L-filter increases with a higher inductance than the LCLfilter the dynamic performance get worse in a high power system. The performance of a LCL-filter is better than a Lfilter in the same inductance conditions. A LCL-filter is more economical, since the required inductance is smaller than it is for a L-filter with the same performance.

The LCL-filter implemented in the system is shown in Fig. 2. The delta connected LCL-filter consists of inductors, a capacitor, and resistors. The rated voltage of the capacitor can be reduce 3 times by a delta-connected LCL-filter, when compared to a wye-connected-LCL filter. The resistor is used as a damping resistor to restrain the resonance.
TABLE I

ANGLE OF SEMiciRCLE In FAulty Modes

\begin{tabular}{c|c}
\hline $\boldsymbol{\theta}$ & Fault switch \\
\hline $30^{\circ} \sim 90^{\circ}$ & S3 fault(F3) \\
\hline $90^{\circ} \sim 150^{\circ}$ & S5 fault(F5) \\
\hline $150^{\circ} \sim 210^{\circ}$ & S1 fault(F1) \\
\hline $210^{\circ} \sim 270^{\circ}$ & S6 fault(F6) \\
\hline $270^{\circ} \sim 330^{\circ}$ & S2 fault(F2) \\
\hline $330^{\circ} \sim 30^{\circ}$ & S4 fault(F4) \\
\hline
\end{tabular}

\section{The Proposed Fault Detection Method}

\section{A. Concept of fault diagnosis}

A flow chart for the proposed fault diagnosis and the tolerant algorithm is illustrated in Fig. 3. This system consists of five major steps.

The measured current data which is used for a feature extraction system is stored and regularly updated in the data storage step.

In the feature extraction system, the significant assignment which is an analysis of the current is performed for detecting faulty switches. The transformation to a stationary reference frame is done and the attributes of the current pattern such as the surface and the angle can be obtained.

During the fault detection step, faulty switches can be diagnosed and identified using the attributes acquired from the previous step. The outputs of the fault diagnosis step can have $-3,-2,-1,0,1,2$, and 3 . These indicate whether or not a fault has occurred in a switching device and in which switch the fault has occurred.

If a fault has occurred, the fault tolerant algorithm which reconfigures the entire system to isolate the faulty converter is executed for proper performance under faulty conditions.

\section{B. Current pattern observation}

A three-phase current of six-converters is measured as shown in Fig. 1. The measured current $\left(i_{a}, i_{b}, i_{c}\right)$ can be transformed into two-dimension $\left(i_{d}, i_{q}\right)$ by Eq. (2).

$$
\begin{gathered}
i_{d}^{s}=\frac{2}{3} i_{a}^{s}-\frac{1}{3} i_{b}^{s}-\frac{1}{3} i_{c}^{s} \\
i_{q}^{s}=\frac{1}{\sqrt{3}}\left(i_{b}^{s}-i_{c}^{s}\right) .
\end{gathered}
$$

The current pattern which indicates the location of the faulty switch can be distinguished into six-patterns.

The shape of the current pattern in a healthy condition is a circle. If an open switch fault has occurred, the phase current where the fault occurred has only a positive or a negative value. A semicircle shape, therefore, represents an open fault condition as shown in Fig. 4. The angle of the semicircle corresponds to the location of the faulty switching device in Table I. 


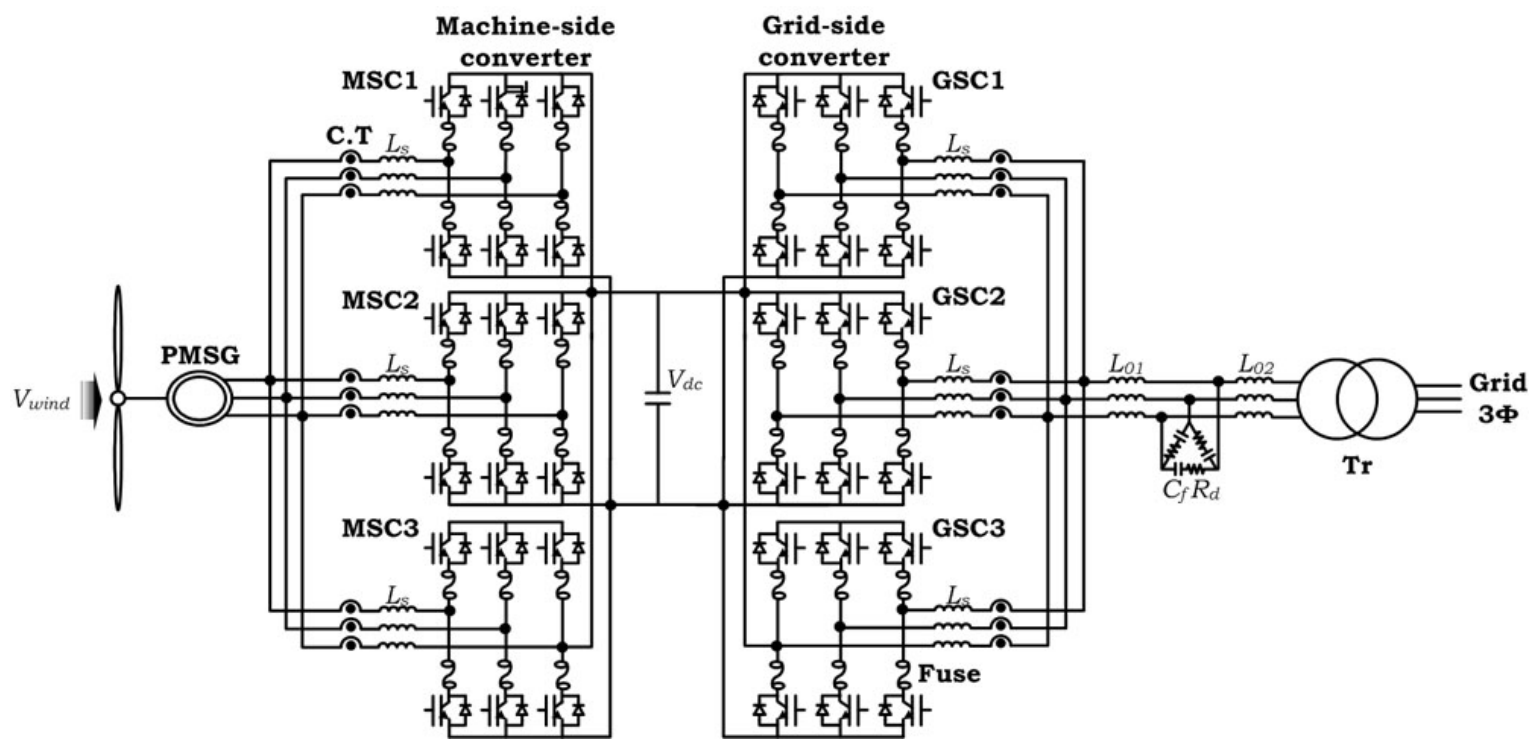

Fig. 1. A three-parallel power converter for a wind turbine.

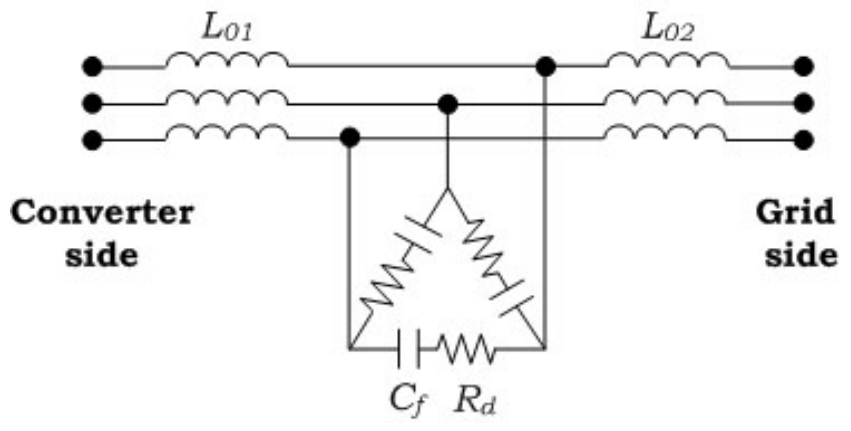

Fig. 2. Delta-connected LCL-filter.

TABLE II

FuZZY RULE TABLE

\begin{tabular}{c|c|c|c}
\hline & Positive & Zero & Negative \\
\hline $\mathbf{I}_{\theta 1}$ & S1 fault(F1) & \\
\hline $\mathbf{I}_{\theta 2}$ & S2 fault(F2) & \\
\hline $\mathbf{I}_{\theta 3}$ & S3 fault(F3) & \multirow{2}{*}{ NO fault(F0) } \\
\hline $\mathbf{I}_{\theta 4}$ & S4 fault(F4) & \\
\hline $\mathbf{I}_{\theta 5}$ & S5 fault(F5) & \\
\hline $\mathbf{I}_{\theta 6}$ & S6 fault(F6) & \\
\hline
\end{tabular}

\section{Methodology of a fuzzy based approach}

The proposed fault diagnosis technique is based on the analytic and the heuristic characters of a PWM converter. A conventional tool, binary logic, is not suited for processing uncertain and doubtful data. On the other hand, a fuzzy system can properly deal with linguistic expression and reasoning processes by employing if-then rules.

The membership functions can be chosen to take into consideration the maximum performance or the reduction of

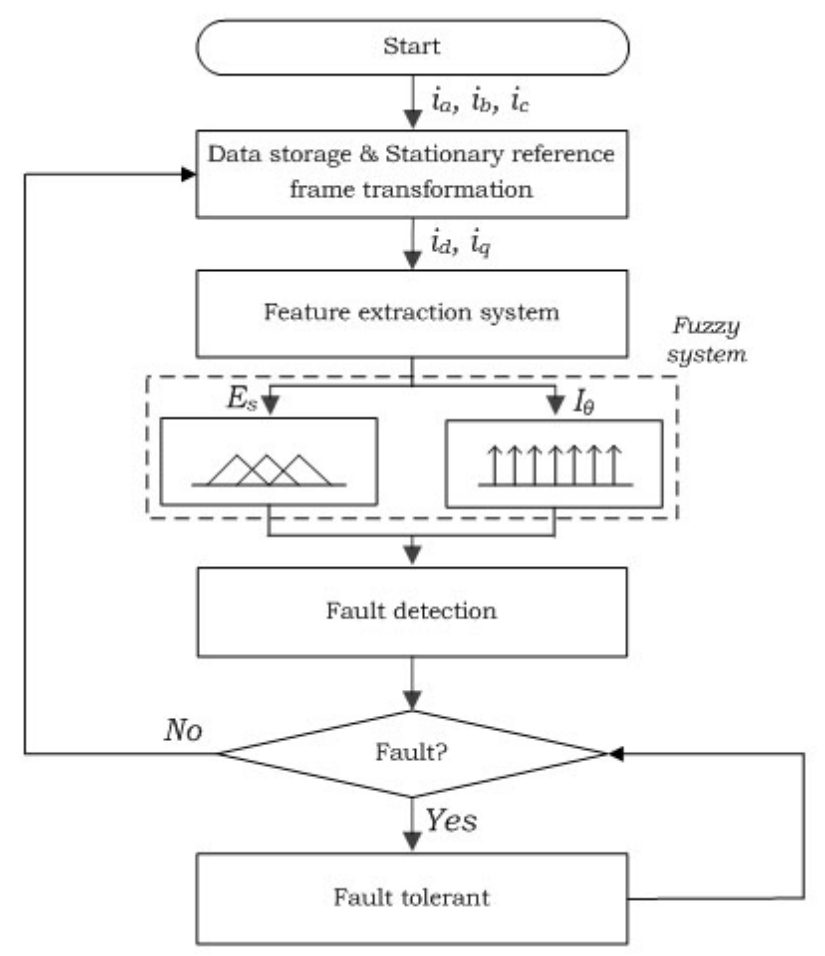

Fig. 3. Flow chart of fault diagnostic system.

computational effort. The fuzzy system in this paper adopts a triangle and a singleton shape as the input membership functions and the output membership function adopts a singleton shape for reducing the computational effort and the processing time as shown in Fig. 5.

There are various defuzzification methods [11]-[13]. The centroid of the area is used for defuzzification in our system.

In our system, two factors are used for input variables of the fuzzy system.

1) The surface difference $\left(E_{s}\right)$ of the current patterns be- 


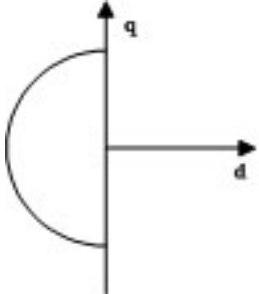

S1 fault

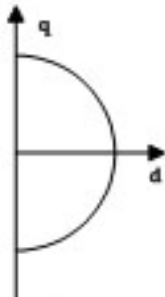

S4 fault

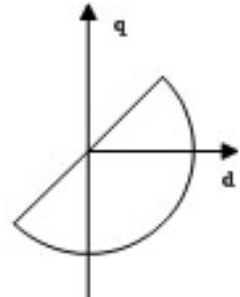

S2 fault

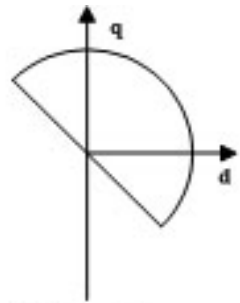

S3 fault

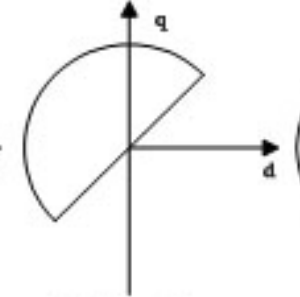

S5 fault

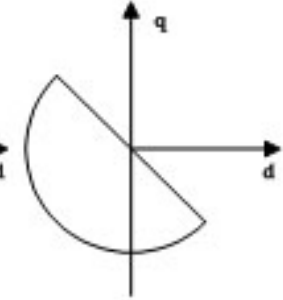

S6 fault
Fig. 4. Current patterns in faulty modes.
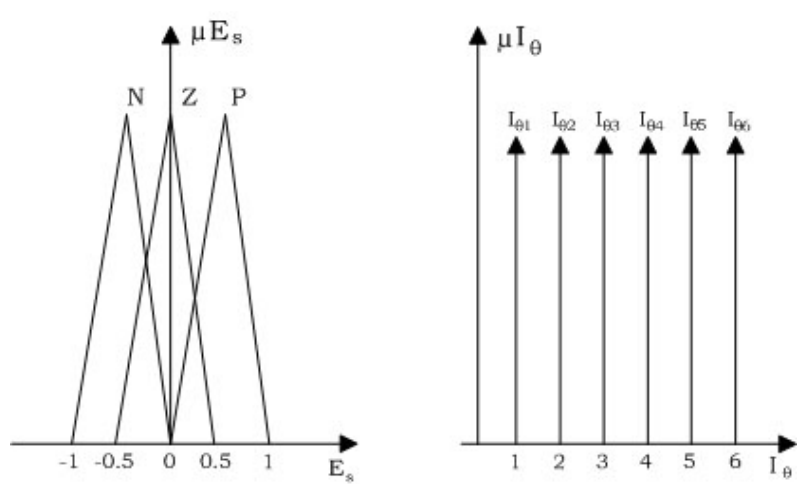

(a)

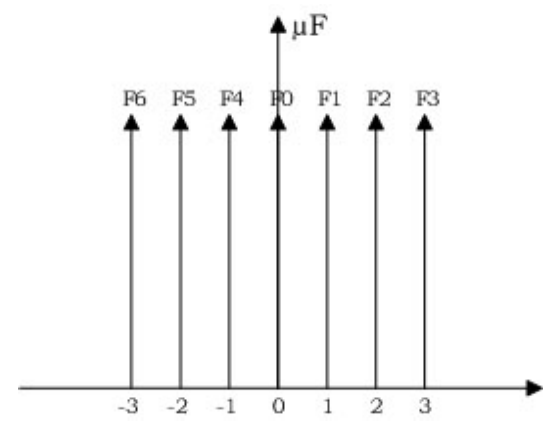

(b)

Fig. 5. Membership functions of (a) input variables and (b) output variable

tween a healthy condition and a faulty condition as shown in Fig. 6.

$$
E_{s}=S_{h}-S_{f}
$$

where, $S_{h}$ is the current vector surface in the healthy mode and $S_{f}$ is the current pattern surface in the faulty mode.

2) The angle of the current patterns $\left(I_{\theta}\right)$ in Fig. 6 .

$$
I_{\theta}=\tan ^{-1}\left(q_{c m} / d_{c m}\right)
$$

where, $d_{c m}$ is the center of the d-frame and $q_{c m}$ is the center of the q-frame.
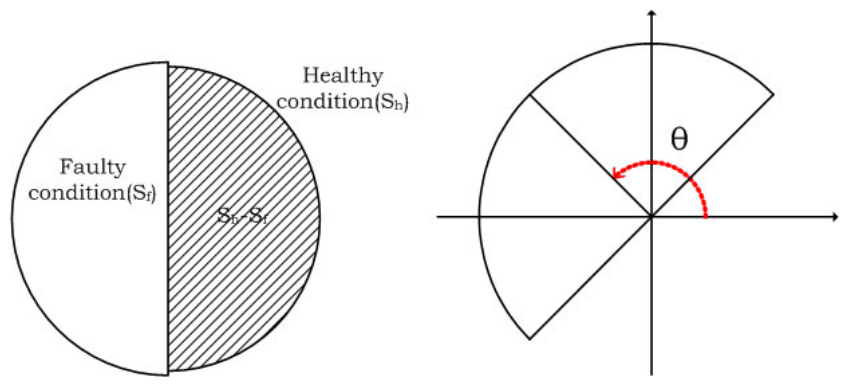

Fig. 6. Definition of $\mathrm{E}_{s}$ and $\mathrm{I}_{\theta}$.

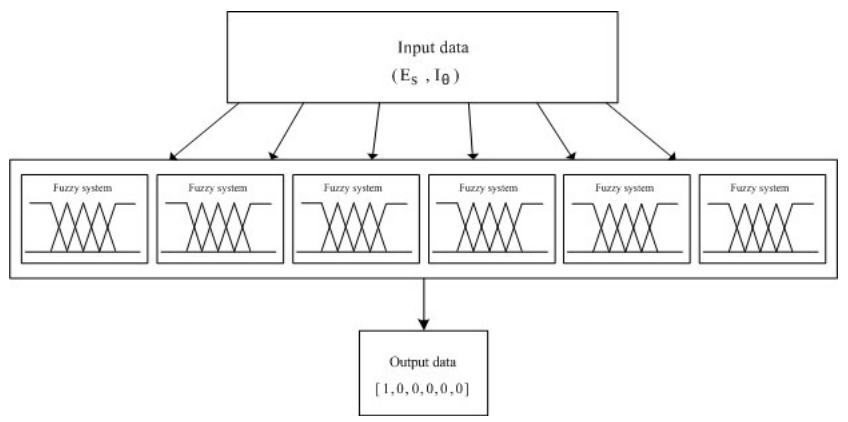

Fig. 7. Implementation of the fuzzy system.

Let us explain mathematically how to obtain the information of the current pattern. The current is sensed at an interval of the processing period. The fan region of $(N, 0, N+1)$ can be regarded as a triangular shape because the processing period is very short. The surface of the triangle can be easily calculated and the surface of the current pattern can be obtained.

$I_{\theta}$ is calculated by an angle between the origin and the center of mass.

The fuzzy rule table is shown in Table II. A fault is detected if $E_{s}$ is positive and the location of the faulty switch can be identified from the information of $I_{\theta}$.

The fuzzy system mentioned above is applied to each of the six-converters as shown in Fig. 7. The attributes of the current vector for each converter are respectively entered into the fuzzy system and the size of the output is [16].

\section{Fault tolerant strategy for a three-parallel power conver- sion system}

If a fault has occurred at any switch and the operation continues under this condition, some secondary troubles can arise. An additional fault can occur in healthy switches due to an over-current and the generator can be destroyed by the noise and vibration.

Proper operation under faulty conditions is guaranteed by a reconfiguration of the power conversion system. The system can be reconfigured by isolating the faulty converter as can be seen in Fig. 8 and the switching signal for two-parallel operation should be transmitted to healthy converters. Faulty converter isolation can be accomplished by opening the triac. The generated output may decrease but the secondary problems can be prevented and normal operation is possible while the faulty switches are repaired by this fault tolerant algorithm. 


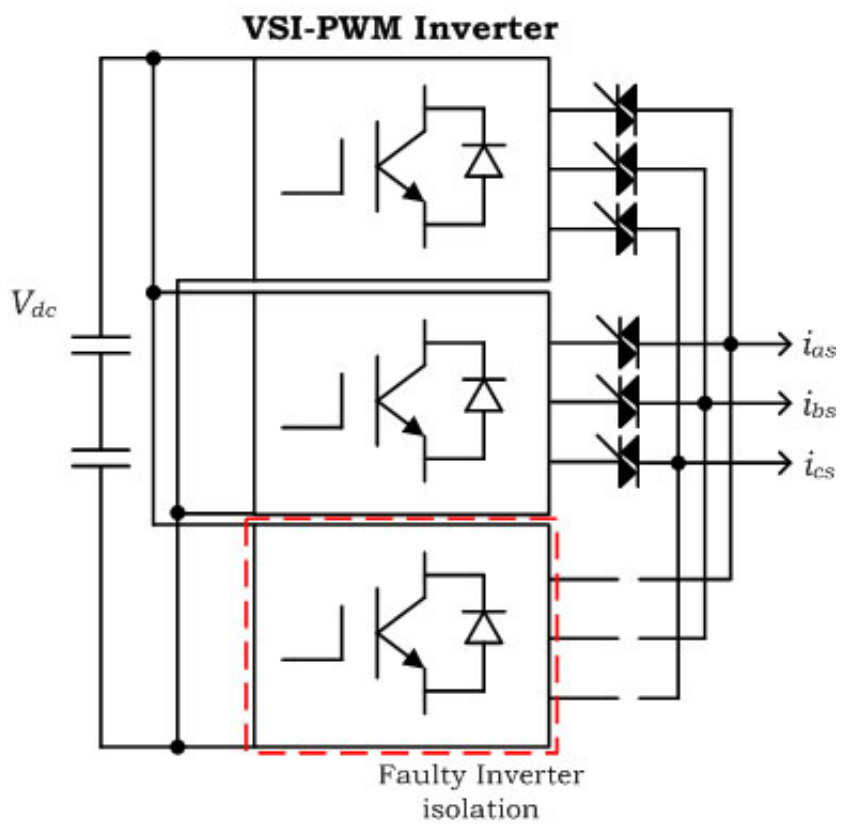

Fig. 8. System reconfiguration in a faulty mode.
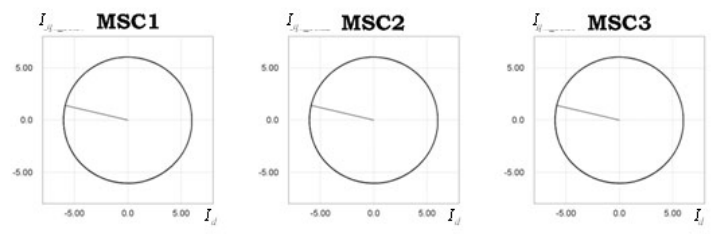

(a)
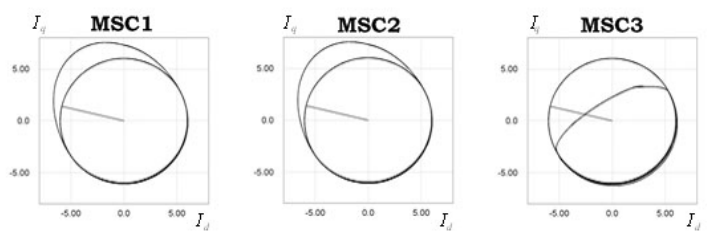

(b)

Fig. 9. Current patterns of three-parallel converter in (a) healthy mode and (b) faulty mode.

\section{Simulation Results}

The proposed technique has been implemented to confirm its reliability in the steady state by using a PSIM simulation. The simulated system is composed of a PMSG, a 3-parallel back-to-back converter and 18 current sensors. The PWM signal transmitted to an ideal IGBT which is employed as a switching device is forced to zero to simulate an open switch fault condition. The simulation parameters are given in Table III.

The current patterns under healthy and faulty conditions are illustrated in Fig. 9 (a) and (b), respectively. The current pattern is a circle shape under the healthy condition as shown in Fig. 9 (a). The current pattern of a faulty converter has a semicircle shape as shown in Fig. 9 (b), namely the currents cannot flow through the faulty switch. However, the currents of the other converters have been increased in order to maintain the rated power.

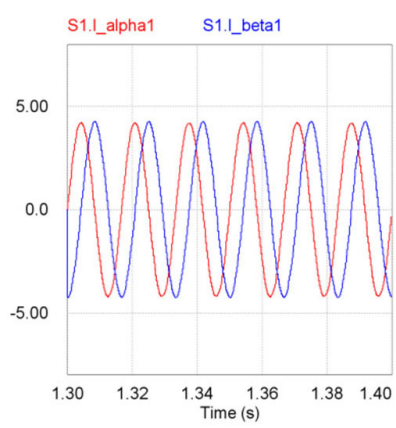

(a)

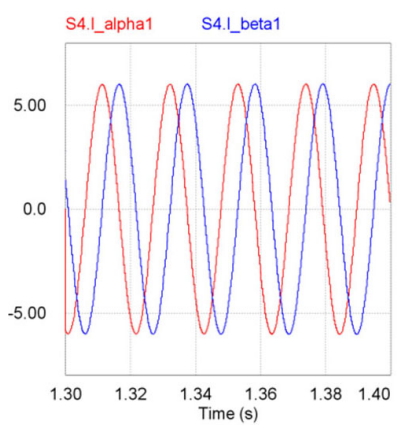

(b)
Fig. 10. $I_{d}-I_{q}$ of (a) grid-side and (b) machine-side.

TABLE III

Simulation PARAmETERS OF THE 10KW Wind System

\begin{tabular}{c|c|c}
\hline \multirow{4}{*}{ Machine side } & Rated power & $11 \mathrm{~kW}$ \\
\cline { 2 - 3 } & Rated rotor speed & $1450 \mathrm{rpm}$ \\
\cline { 2 - 3 } & Rated torque & $72 \mathrm{Nm}$ \\
\hline \multirow{2}{*}{\begin{tabular}{c} 
converter \\
\cline { 2 - 3 }
\end{tabular}} & Switching frequency & $2 \mathrm{kHz}$ \\
\cline { 2 - 3 } & DC-link Voltage & $600 \mathrm{~V}$ \\
\cline { 2 - 3 } Grid side & DC-link Capacitance & $3300 \mathrm{uF}$ \\
\cline { 2 - 3 } & Rated output power & $10 \mathrm{~kW}$ \\
\cline { 2 - 3 } & Grid line-to-line voltage & $380 \mathrm{~V}$ \\
\cline { 2 - 3 } & frequency & $60 \mathrm{~Hz}$ \\
\hline
\end{tabular}

$i_{d^{-}} i_{q}$ of the grid-side and the machine-side are shown in Fig. 10, respectively. The grid-side current is 4.2Apeak and $60 \mathrm{~Hz}$. The machine-side current is $6 \mathrm{Apeak}$ and $50 \mathrm{~Hz}$, and the generator is operating at $960 \mathrm{rpm}$.

Fig. 11 and 12 show the $i_{d}-i_{q}$ current and the fuzzy output indicating the location of a switch in which a fault has occurred. The fuzzy outputs when faults occur on the machineside and the grid-side are respectively illustrated.

Fig. 11 is a case where a fault has occurred on the machineside (MSC2-S6) and the fuzzy output is a negative three. The fault occurred at $1.5 \mathrm{sec}$ and its detection is accomplished after 1.5 periods of current.

Fig. 12 shows that a fault has occurred on the grid-side (GSC2-S1) and the fuzzy output is positive one. The fault occurred at $1.5 \mathrm{sec}$ and its detection time is one period of the grid-side current.

\section{EXPERIMENTAL RESUlts}

The proposed technique is applied to a three-parallel power converter in a $10 \mathrm{~kW}$ wind turbine simulator. The experimental setup which is composed of the MG-set, a controller board, and a three-parallel power converter is described in Fig. 13 (a), (b), and (c), respectively. The PMSG is used as a generator. The digital controller is based on a digital signal processor (TMS320F28335). The rated values and the parameters of the system are identical to those in the simulation and the wind speed is $8.5 \mathrm{~m} / \mathrm{s}$.

Fig. 14 shows the stator current, the current vector, and the fuzzy output of the machine-side under the healthy condi- 


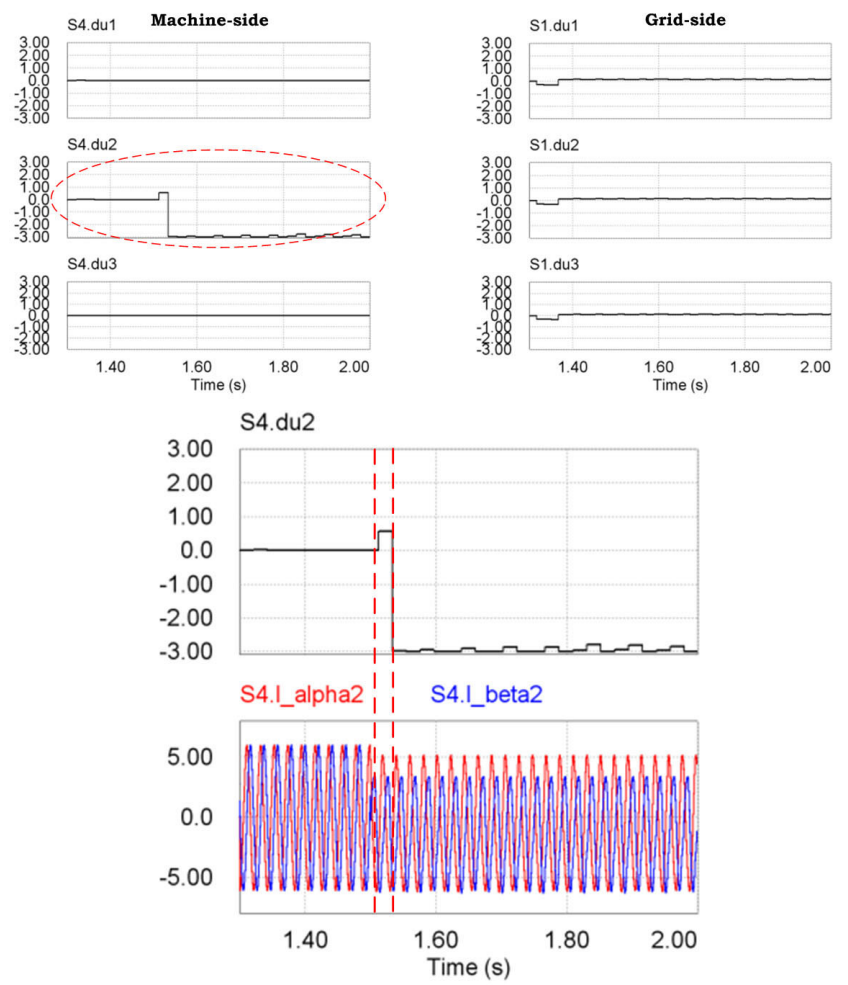

Fig. 11. Fuzzy outputs in machine-side switch faulty mode and enlarged figure.

tion and the faulty condition, respectively. The machine-side current flows at about 10A. Fig. 14 (b) is when a fault has occurred at S2 and the fuzzy output is positive two. Fig. 14 (c) is when a fault has occurred at S6 and the fuzzy output is negative three. In both cases, it takes two periods of current to detect the fault.

The grid-side case is shown in Fig. 15. The current is 2.5A. When faults occur at S1 and S5, the fuzzy outputs are positive one and negative two, respectively. The faults are detected within two periods.

It is verified that one to two periods of current are needed to identify faulty switches as can be seen in Fig. 14 and 15 .

\section{CONCLUSION}

A fault diagnosis system and a fault tolerant algorithm for three-parallel power conversion systems are proposed, and these techniques are verified through simulations and experimental results. The experiment is realized by a $10 \mathrm{~kW}$ simulator. The considered fault types are switching device open and short faults. Faulty switches can be identified by a pattern analysis of the current which is transformed by the Concordia transformation. The surface and the angle of the current patterns are the major factors for detecting faulty switches. A robust algorithm is, especially, needed for getting the correct angle because an inaccurate value can lead to incorrect results. The proposed fault detection technique using the current vector has some advantages. Additional sensors and complicated calculations are not needed. Therefore, it is possible to cut costs. Faulty switch detection and identification can be completed within two periods of current. Finally, a
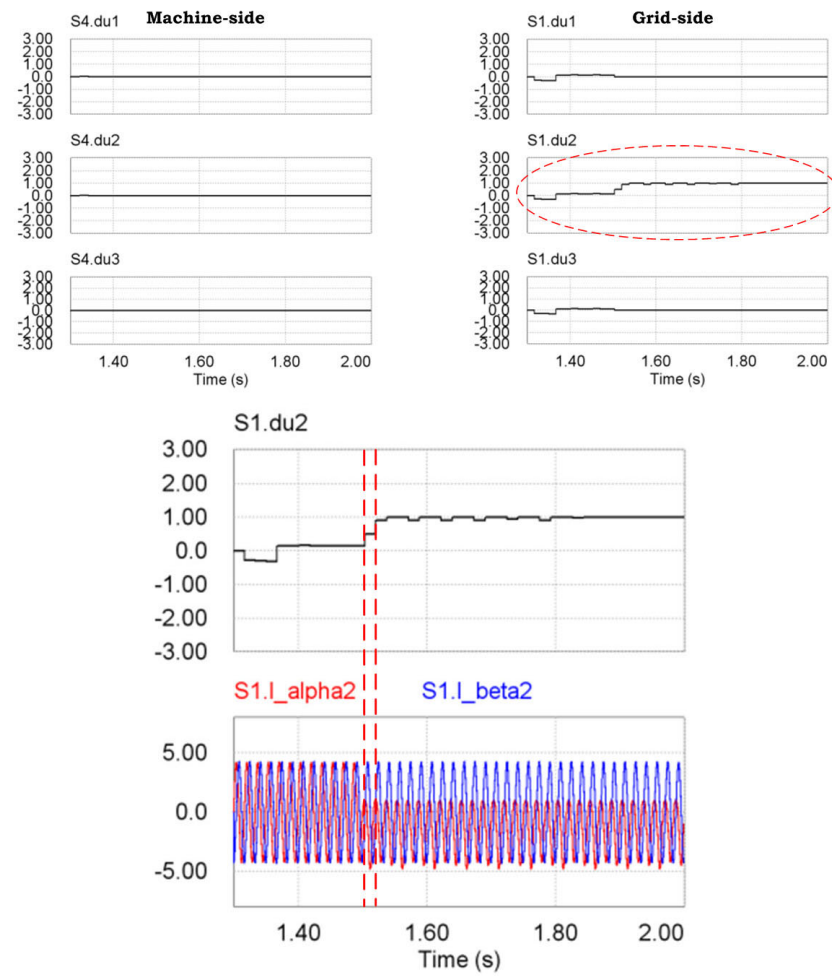

Fig. 12. Fuzzy outputs in grid-side switch faulty mode and enlarged figure.

fault tolerant algorithm is proposed for proper operation under the fault condition. The purpose of this algorithm can be achieved by isolating the faulty converter. Simulations and experimental results have shown the current vectors and fuzzy outputs corresponding to the location of the faulty switches.

\section{ACKNOWLEDGMENT}

This work has been supported by KESRI (Korea Electrical Engineering and Science Research Institute) (2009T100100568), which is funded by MKE (Ministry of Knowledge Economy). 


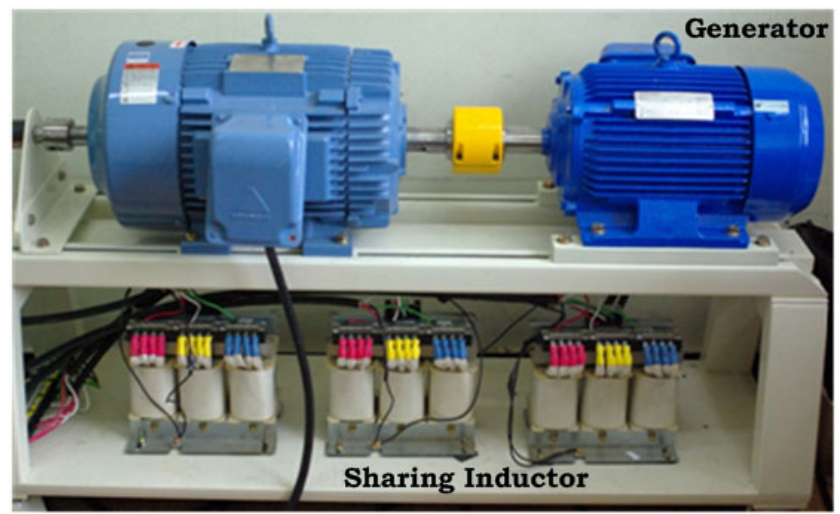

(a)

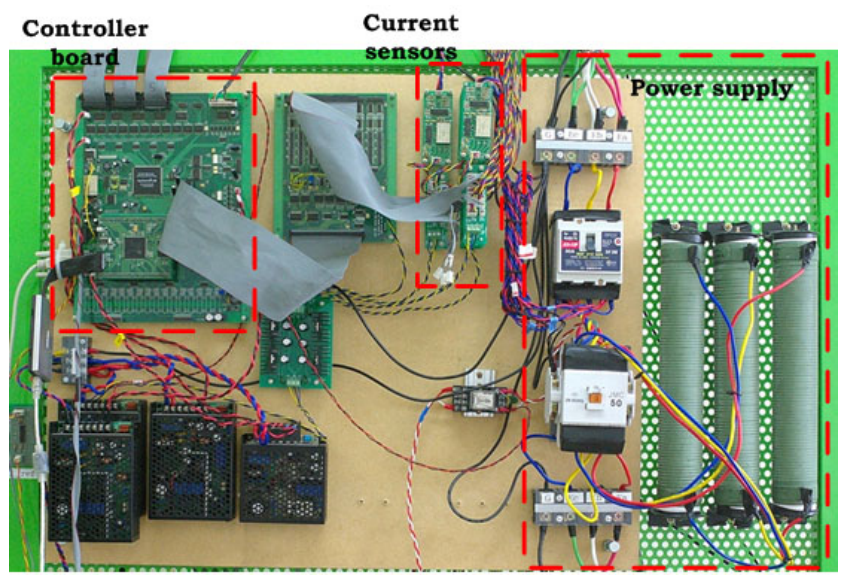

(b)

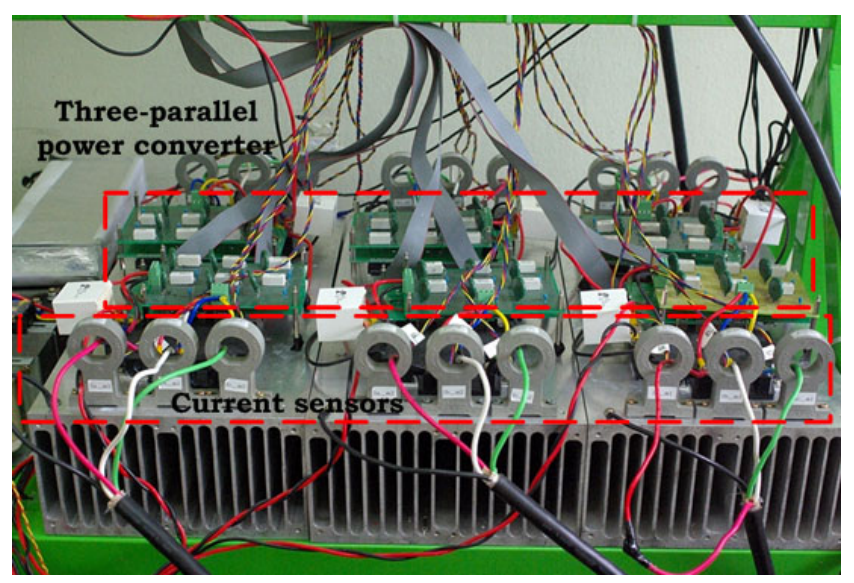

(c)

Fig. 13. Experimental setup. (a) M-G set. (b) Controller board. (c) Three-parallel power converter.

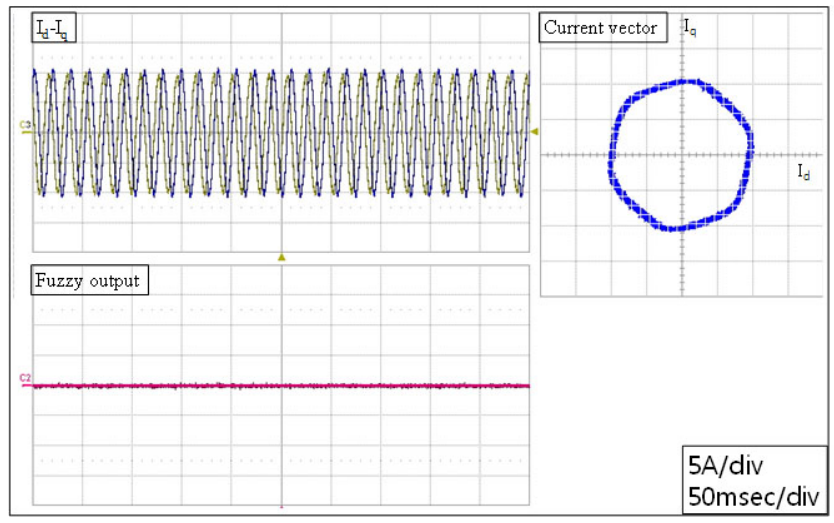

(a)

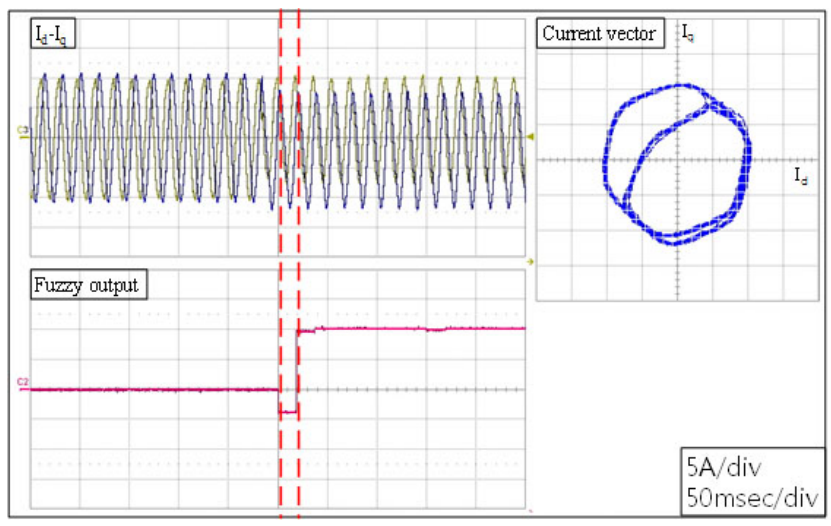

(b)

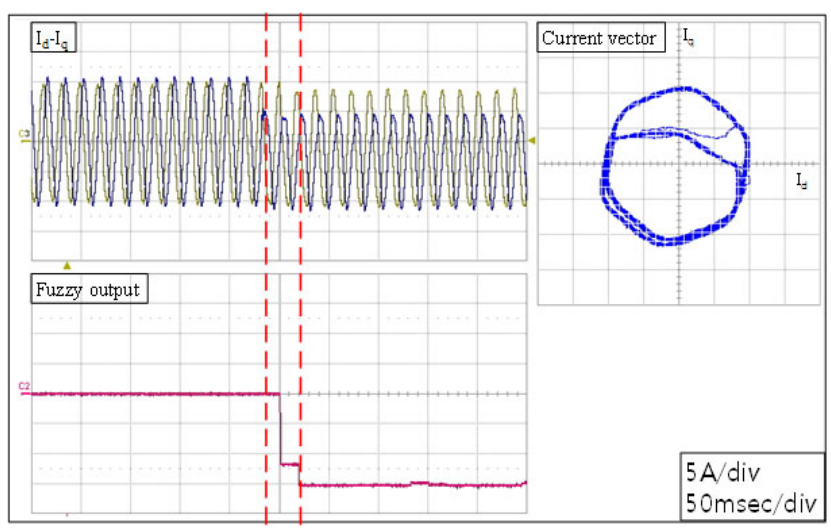

(c)

Fig. 14. Machine-side. (a) Healthy, (b) S2 fault, and (c) S6 fault. 


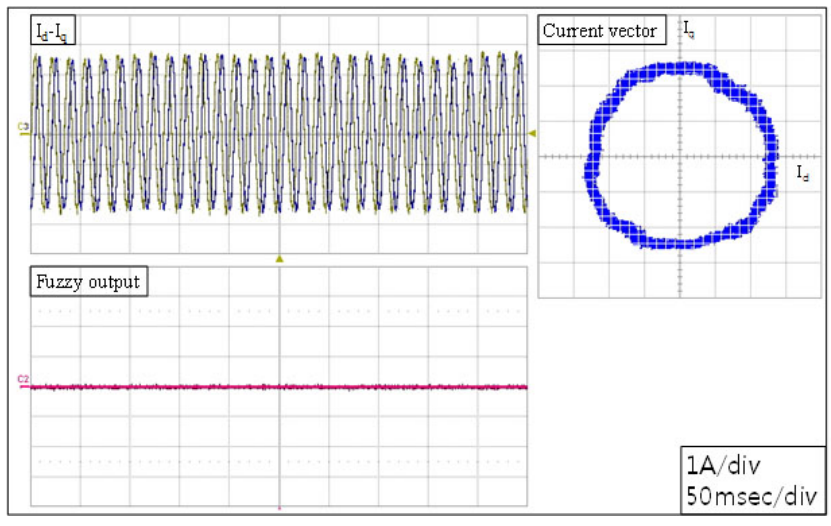

(a)

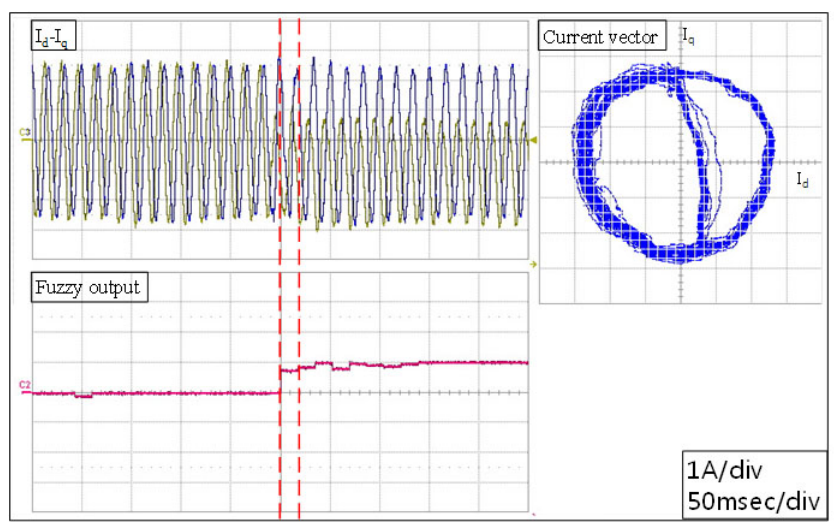

(b)

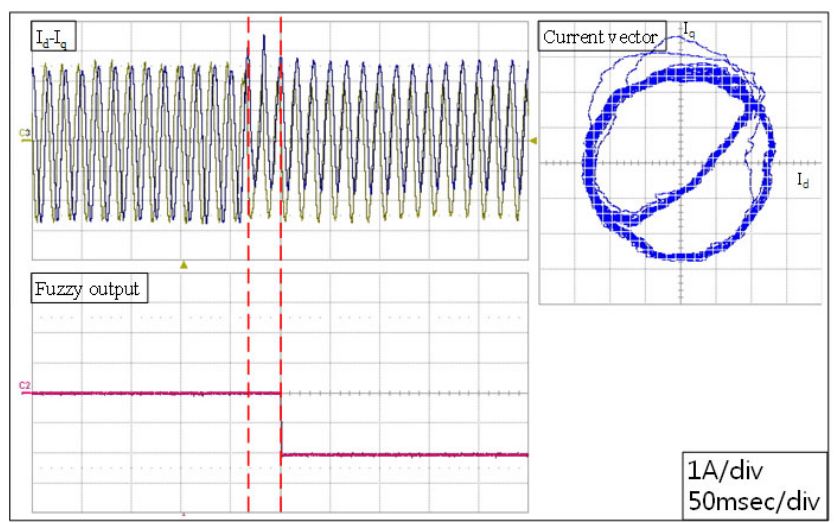

(c)

Fig. 15. Grid-side. (a) Healthy, (b) S1 fault, and (c) S5fault.

\section{REFERENCES}

[1] D. Kastha and B. K. Bose, "Investigation of fault modes of voltagefed inverter system for induction motor drive," IEEE Trans. Industry Applications, Vol. 30, No. 4, pp. 1028-1038, Jul./Aug. 1994.

[2] D. E. Kim and D. C. Lee, "Fault diagnosis of three-phase PWM inverters using wavelet and SVM," Journal of Power Electronics, Vol. 9, No. 3, pp. 377-385, Jun. 2009.

[3] R. L. de Araujo Ribeiro, C.B. Jacobina, E.R.C. da Silva, and A.M.N. Lima, "Fault detection of open-switch damage in voltage-fed PWM motor drive system," IEEE Trans. Power Electronics, Vol. 18, No. 2, pp. 587-593, Mar. 2003.
[4] S. M. Jung, J. S. Park, H. S. Kim, H. W. Kim, and M. J. Youn, "Simple switch open fault detection method of voltage source inverter," IEEE ECCE, pp. 3175-3181, Sep. 2009.

[5] R. Peuget, S. Courtine, and J. P. Rognon, "Fault detection and isolation on a PWM inverter by knowledge-based model," IEEE Trans. Industry Applications, Vol. 34, No. 6, pp. 1318-1326, Nov./Dec. 1998.

[6] F. Zidani, D. Diallo, M. El Hachemi Benbouzid, and R. Naït-Saïd, "A fuzzy-based approach for the diagnosis of fault modes in a voltagefed PWM inverter induction motor drive," IEEE Trans. Industrial Electronics, Vol. 55, No. 2, pp. 586-593, Feb. 2008.

[7] F. Zidani, M. E. H. Benbouzid, D. Diallo, and M. S. Naït-Saïd, "Induction motor stator faults diagnosi by a current concordia patternbased fuzzy decision system," IEEE Trans. Energy conversion, Vol. 18, No.4, pp. 469-475, Dec. 2003.

[8] S. Khomfoi and L. M. Tolbert, "Fault diagnostic system for a multilevel inverter using a neural network," IEEE Trans. Power Electronics, Vol. 22, No. 3, pp. 1062-1069, May 2007.

[9] S. S. Kwak, "Investigation of fault-mode behaviors of matrix converters," Journal of Power Electronics, Vol. 9, No. 6, pp. 949-959, Nov. 2009.

[10] K. W. Park and K. B. Lee, "Hardware Simulator Development for a 3Parallel Grid-connected PMSG Wind Power System," Journal of Power Electronics, Vol. 10, No. 5, pp. 555-562, Sept. 2010.

[11] R. M. Santos Filho, P. F. Seixas, P. C. Cortizo, L. A. B. Torres, and A F. Souza, "Comparison of three single-phase PLL algorithms for UPS applications," IEEE Trans. Industrial Electronics, Vol. 55, No. 8, pp. 2923-2932, Aug. 2008.

[12] H. G. Jeong, K. B. Lee, S. W. Choi, and W. J. Choi, "Performance improvement of LCL-filter based grid connected-inverters using PQR power transformation," IEEE Trans. on Power Electronics, vol. 25, no. 5, pp. 1320-1330, May. 2010.

[13] D. G. Yoon, H. G. Jeong and K. B. Lee, "The Design of an LCL-filter for the Three-Parallel Operation of a Power Converter in a Wind Turbine,' IEEE ECCE (Energy Conversion Congress \& Expo.), pp. 1537-1544, Sept. 2010.

[14] B. K. Bose, Power Electronics and Motor Drives, Academic Press, 2007.

[15] A. Nasri, A. Hazzab, I. K. Bousserhane, S. Hadjeri, and P. Sicard, "Fuzzy Logic Speed Control Stability Improvement of Lightweigh Electric Vehicle Drive," Journal of Electrical Engineering \& Technology, vol. 5, no. 1, pp. 129-139, Mar. 2010.

[16] V. A. Wadnerkar, M. M. Bhaskar, T. R. Das, and A. D. Rajkumar, "A New Fuzzy Logic based Modeling and Simulation of a Switched Reluctance Motor," Journal of Electrical Engineering \& Technology, vol. 5, no. 2, pp. 276-268, Jun. 2010.

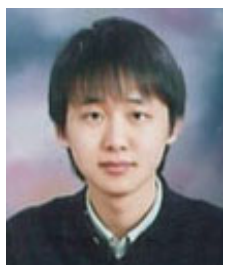

Young-Jong Ko was born in Daejeon, Korea, in 1985. $\mathrm{He}$ received his B.S. in Electronic Engineering from Ajou University, Suwon, Korea, in 2009. He is currently working toward his M.S. at Ajou University. His research interests include power conversion and gridconnected systems.

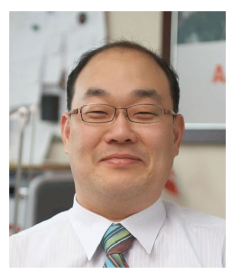

Kyo-Beum Lee was born in Seoul, Korea, in 1972. He received his B.S. and M.S. in Electrical and Electronic Engineering from Ajou University, Korea, in 1997 and 1999, respectively. He received his Ph.D. in Electrical Engineering from Korea University, Korea in 2003 From 2003 to 2006, he was with the Institute of Energy Technology, Aalborg University, Aalborg, Denmark. From 2006 to 2007, he was with the Division of Electronics and Information Engineering, Chonbuk National University, Jeonju, Korea. In 2007 he joined the School of Electrical and Computer Engineering, Ajou University, Suwon, Korea. He is an Associated Editor of the IEEE Transactions on Power Electronics and the Journal of Power Electronics. His research interests include electric machine drives and renewable power generation. 